\title{
The performance test of the car catalytic converter in the conditions of urban operation
}

\author{
Aleksandr Ivanov ${ }^{1, *}$, Oleg Abyzov ${ }^{1}$, Yurii Galyshev ${ }^{1}$, and Victor Rumyantsev ${ }^{1}$ \\ ${ }^{1}$ Peter the Great St. Petersburg Polytechnic University, Saint Petersburg, 195251, Russian Federation
}

\begin{abstract}
In the conditions of continuous operation of a car tests of its engine for compliance with the declared environmental class on specialized test benches seem to be quite costly and laborious. Given this circumstance, in this paper a simplified method for verifying the operability of converters is proposed including the assessment of the influence of certain operation modes and some operational factors on the amount of hydrocarbons and carbon monoxide emissions. Efficiency of the converter was estimated by comparing the experimental data on the emissions of these toxic components in the exhaust system before and after the converter. To test the efficiency of the converter, the cold start and warm-up modes of the engine were selected and investigated, as well as several modes close to those typical for testing the engine and car in urban areas according to the European Driving Cycle. As operational factors, typical malfunctions were investigated that often occur during the operation of an engine and significantly increase the amount of harmful emissions. A criterion is proposed for evaluating the performance of the converter and recommendations are given to increase the efficiency of the converter to meet the certain emission standards for cars with sparkignition engines.
\end{abstract}

\section{Introduction}

Currently, cars with IC engines remain the most widespread, despite the gradual increase of the share of null-emission engines. Therefore, the problem of further pollution of air in large cities by toxic components of exhaust gases remains very relevant [1,2].

The widespread use of catalytic converters has proven to be effective method of reducing toxicity of exhaust gases throughout the engine life cycle $[3,4]$. For the purpose of testing for compliance with the declared emission standards the cars are subjected to test procedures including the so-called standard driving cycle [5]. The New Modified European Driving Cycle (NMEDC) is adopted in most European countries including Russia and is supposed to simulate traffic conditions in the city and partially the extra-urban mode. The driving cycle shown in Fig. 1 consists of two sub-cycles: urban driving cycle and extraurban driving cycle. Operational modes of the urban cycle represent the average statistical data on driving in the intense urban traffic conditions and consist of 4 repeated phases. Phase 1 of the test commences immediately after the cold start.

* Corresponding author: alkoniv@mail.ru 
After the cold start and in the first seconds of tests on the urban driving cycle the car engine operates in modes that impede the compliance for declared toxicity standards. Forced use of the enriched air-fuel mixture for reliable start-up and subsequent stable operation of an unheated engine reduces the efficiency of oxidative reactions in the converter in conditions of oxygen deficiency, which leads to a significant increase in emissions of hydrocarbons $(\mathrm{CH})$ and carbon monoxide $(\mathrm{CO})$. It should be noted that intensive oxidation of toxic components in a standard converter starts at $300{ }^{\circ} \mathrm{C}$, despite the search for new ways of oxidizing these components at lower temperatures [6-9]. The closed circuit of the electronic control unit (ECU), which corrects the air-fuel ratio using feedback from the $\mathrm{O}_{2}$ sensor, is activated only at $350{ }^{\circ} \mathrm{C}$ [10]. It means that at cold start it takes some time to warm-up the catalytic converter and $\mathrm{O}_{2}$ sensor to working temperatures at which the converter effectively neutralizes harmful components of the exhaust gases. Since the test procedure for compliance of a car to standards higher than Euro-3 starts with the selection of the exhaust gases immediately after the cold start, any delay in the work of the catalytic converter results in high contents of $\mathrm{CO}$ and $\mathrm{CH}$ in exhaust gases.

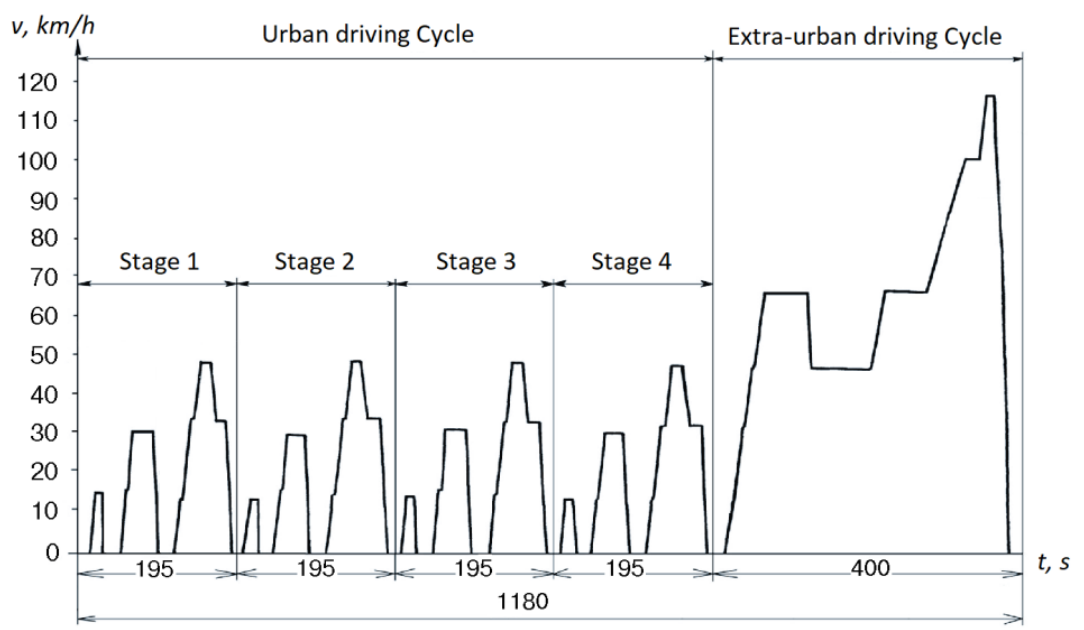

Fig. 1. The New Modified European Driving Cycle (NMEDC).

It has also been reported that at transient operation modes of engine (i.e. rapid acceleration or rapid braking) during the NMDEC maximums of $\mathrm{CO}$ and $\mathrm{CH}$ emissions are much higher than at steady-state operation mode [11]. Furthermore, the catalytic converter degrades with time because of thermal aging and chemical poisoning $[12,13]$.

The factors mentioned above tell us that widely adopted in diagnostics method of checking the catalytic converter's operability by the difference of sinusoidal readings of two $\mathrm{O}_{2}$ sensors cannot guarantee the fulfillment of the declared environmental class standards. During the start, idle and acceleration the air-fuel ratio deviates from stoichiometric to rich, so that throughout the several consequent working cycles voltage signals of $\mathrm{O}_{2}$ sensor reach their maximums then return to their initial values. The duration of these transient processes depends on enrichment ratio of the mixture determined by the ECU and the sensor signals. At such operation modes it is almost impossible to track the catalyzer efficiency by the comparison of readings of two $\mathrm{O}_{2}$ sensors. The only way to quantitatively assess the reduction of the $\mathrm{CO}$ and $\mathrm{CH}$ content in the exhaust gases is to provide gas analysis.

There are a number of factors that emerge during the life cycle of a car associated with engine malfunctions, the impact of which may impede the unconditional fulfillment of existing standards for the emissions of hydrocarbons $(\mathrm{CH})$ and carbon monoxide $(\mathrm{CO})$ 
within the declared environmental class. Among the malfunctions that most affect the amount of harmful emissions are misfires in cylinders that are caused by problems with ignition system, fuel system or the $\mathrm{O}_{2}$ sensor. Even the short-time exposure of the catalytic converter to operational malfunctions listed can lead to the situation when declared emission standard is exceeded.

For performing a standard driving cycle test of a car and its engine a test bench is required including rollers and special equipment. In the conditions of continuous operation of a car, the implementation of such a test procedure seems to be quite costly and laborious. Given this circumstance, this paper presents the results of the simplified assessment of the impact of individual modes and the aforementioned operational factors on the amount of $\mathrm{CH}$ and $\mathrm{CO}$ emissions in order to determine the capabilities of a standard converter to minimize these emissions.

\section{Description of the test method}

Efficiency of the catalytic converter was assessed by comparing the experimental data on $\mathrm{CH}$ and $\mathrm{CO}$ emissions in the exhaust system before and after the converter. Such a method is quite widespread to obtain information on the effect of various materials and structural features of catalytic converters on the amount of toxic emissions, and also performance tests of converters [14-18]. The subject of present research is determination of the effect of various operating conditions and engine malfunctions on the efficiency of reducing $\mathrm{CH}$ and $\mathrm{CO}$ emissions in exhaust gas by the converter.

To obtain experimental data in stationary conditions fully serviceable Chevrolet Cruze and Lada Granta automobiles were used, equipped with 4-cylinder engines with a working volume of $1600 \mathrm{~cm}^{3}$ with multipoint fuel injection into the intake port and standard threecomponent converters. The condition of the converters was previously checked on running engines by comparing the voltage signals coming from the primary and secondary $\mathrm{O}_{2}$ sensors using the ESI[tronic] 2.0 diagnostic software. Comparative tests were carried out using the Bosch FSA-740 diagnostic system, equipped with the BEA-050 gas analyzer with embedded ESA (Emission-System-Analysis) software, which allows to quickly record the values of mentioned toxic components of hydrocarbons $\mathrm{CH}$ (in ppm units) and carbon monoxide $\mathrm{CO}$ (in \% by volume), free oxygen $\mathrm{O}_{2}$ and carbon dioxide $\mathrm{CO}_{2}$ (in \% by volume), and also to calculate the air-fuel ratio of the mixture by gas analysis. These values were recorded using photo and video fixation, a fragment of which is shown in Fig. 2.

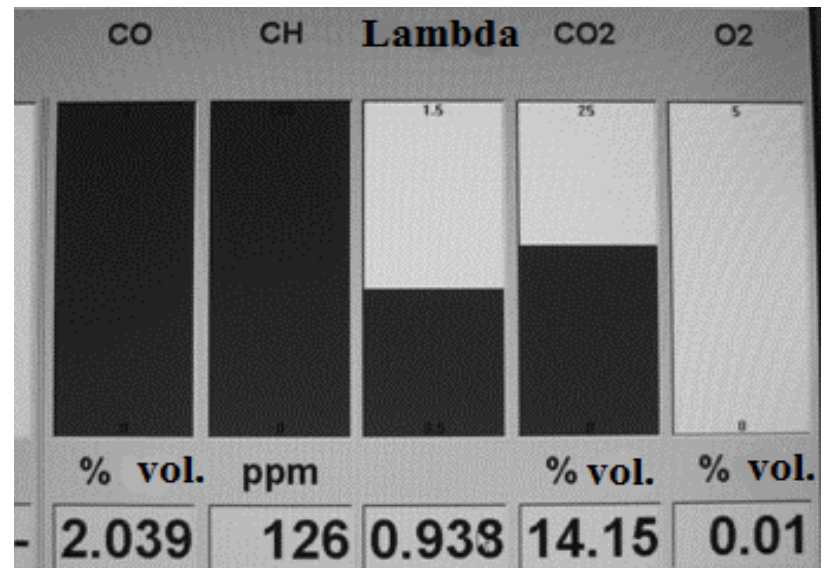

Fig. 2. Fragment of the results of gas analysis and values of air-fuel equivalence ratio (Lambda) obtained using the ESA program. 
The ESI[tronic] 2.0 software also allows instantaneous registration of the values of working fluids temperature, crankshaft rotation speed (n), ignition timing and other engine parameters, as well as to monitor voltage levels on both $\mathrm{O}_{2}$ sensors. The test procedure was divided into two cycles. On the first cycle tests were carried out under the conditions of cold start and engine warm-up, and on the second cycle tests were carried out on the fully warmed up engine at idle and transient modes with low revs (n).

The tests on the first cycle were carried out in a box at initial temperature of $15^{\circ} \mathrm{C}$ and consisted of three stages. The first stage was performed under normal conditions without simulating any malfunctions in the engine control system (ECS) with exhaust gas extraction from the exhaust pipe. At the second stage the control $\mathrm{O}_{2}$ sensor was turned off and the engine run in "open-loop mode" without feedback from the $\mathrm{O}_{2}$ sensor to the ECU simulating a malfunction in the wiring connecting the $\mathrm{O}_{2}$ sensor to the ECU. At the third stage a fitting was installed instead of the $\mathrm{O}_{2}$ sensor and exhaust gas was selected from the exhaust system before the converter. For achieving the identical test conditions, each stage was carried out on different days, so that the engine could completely cool down (to $15^{\circ} \mathrm{C}$ ). The duration of each test stage was $300 \mathrm{~s}$ and was controlled using a stopwatch. The measurements were carried out after $10 \mathrm{~s}$ then $30 \mathrm{~s}$ and then every $30 \mathrm{~s}$ from the engine start. The coolant temperatures were in range from $15^{\circ} \mathrm{C}$ before starting up to $70-75^{\circ} \mathrm{C}$ at the end of the test. With the engine warming up the value of $\mathrm{n}$ gradually decreased from $1100 \mathrm{rpm}$ to $800 \mathrm{rpm}$ and the ignition timing was within the limits set by the ECS.

On the second test cycle four modes of normal engine operation and four modes of operation with imitation of common defects that occur during operation were selected to assess the influence of other previously mentioned factors. The first four modes included idling at constant values of $n=1000$ and $3000 \mathrm{rpm}$, acceleration from 1000 to $3000 \mathrm{rpm}$ with $20 \%$ throttle and braking mode from 3000 to $1000 \mathrm{rpm}$. The choice of such test modes is due to the attempt to approximately reproduce in stationary conditions the unsteady modes of engine operation according the European driving cycle on first and second gears. The remaining four modes were carried out only at steady-state idling modes with the same values of $\mathrm{n}$, but with short-term shutdowns of one cylinder in two different ways. First, one nozzle was turned off, simulating a malfunction in the fuel supply system, and then, the cylinder was turned off by installing a deliberately defective spark plug, simulating a malfunction in the ignition system.

\section{Results and discussion}

The most important results for the first cycle Chevrolet Cruze engine test are presented in Fig. 3 as curves of $\mathrm{CH}$ and $\mathrm{CO}$ emissions versus time of engine operation from start.

Analysis of the data demonstrates that the content of $\mathrm{CO}$ and $\mathrm{CH}$ in first 10-30 seconds after the engine start is quite high independently of gas selection method. However, at the first stage of testing under normal conditions of exhaust gas selection, the content of $\mathrm{CH}$ and $\mathrm{CO}$ is somewhat lower than the content of the same components before the converter. This fact means that reactions of oxidation in the converter initiated shortly after starting a cold engine. The process of elimination of these components went much faster at about $60 \mathrm{~s}$ after the start, which was due to the beginning of the active signaling from the control $\mathrm{O}_{2}$ sensor (according to the ESI [tronic] 2.0 program) and a gradual transition to the stoichiometric mixture. Subsequently, the $\mathrm{CH}$ values gradually decreased, but remained somewhat excessive ( $25-90 \mathrm{ppm}$ ), despite the converter reaching an operating temperature of about $550{ }^{\circ} \mathrm{C}$. It should be noted that throughout the test stage, the $\mathrm{O}_{2}$ content in the exhaust gas was close to zero (not shown in Fig. 3) and it was not enough for the complete oxidation of $\mathrm{CH}$. 


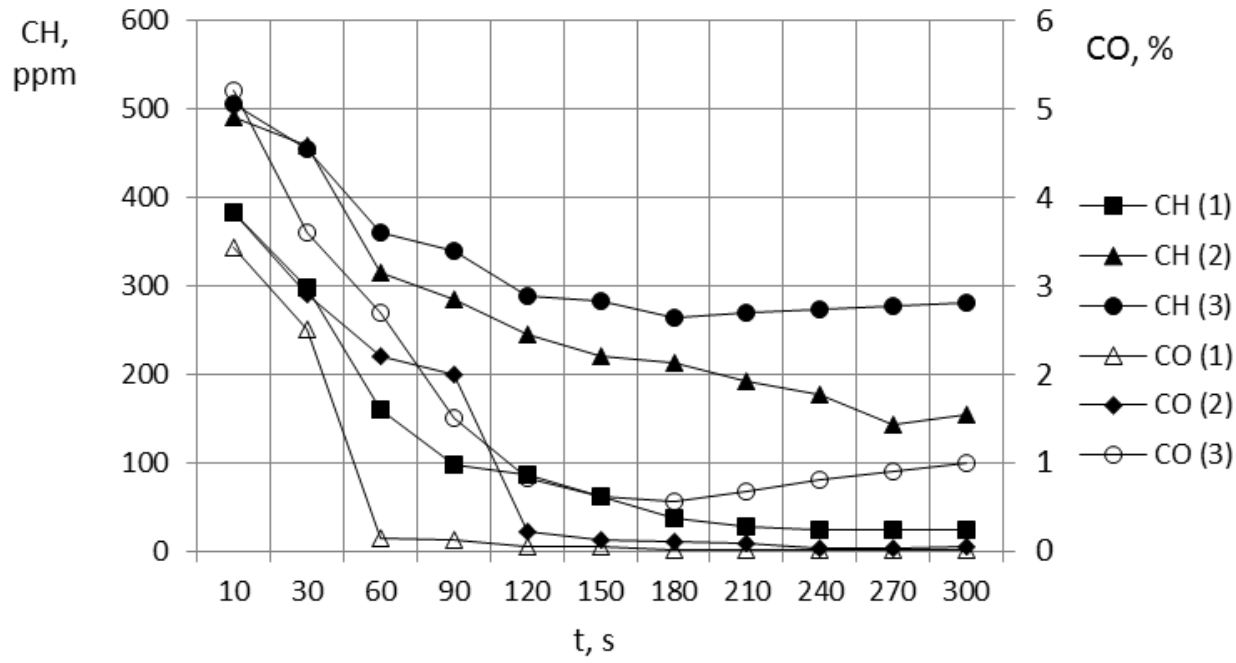

Fig. 3. $\mathrm{CH}$ and $\mathrm{CO}$ contents versus operating time (Chevrolet Cruze engine, cold start): $\mathrm{CH}(1)$ and $\mathrm{CO}(1)$ - values at the first stage of testing under normal conditions; $\mathrm{CH}(2)$ and $\mathrm{CO}(2)$ - values at the second stage without $\mathrm{O}_{2}$ sensor; $\mathrm{CH}(3)$ and $\mathrm{CO}(3)$ - values at the third stage without $\mathrm{O}_{2}$ sensor and with exhaust gas selection before the converter.

The second stage of testing demonstrates the significant raise of $\mathrm{CH}$ content after the converter in the absence of a control voltage from the $\mathrm{O}_{2}$ sensor. This can be attributed to the constant supply of a richer mixture and low content of $\mathrm{O}_{2}$ in the exhaust. At the third stage of the test with the selection of the exhaust gas before the converter the content of $\mathrm{CH}$ and $\mathrm{CO}$ increased even more. However, comparing the test results from the second and third stages, it can be seen that even in the absence of control voltage from the $\mathrm{O}_{2}$ sensor, the converter is able to significantly reduce emissions of $\mathrm{CH}$ and $\mathrm{CO}$ at the engine warmup.

Using the same methodology to assess the $\mathrm{CO}$ and $\mathrm{CH}$ correlations with time at start-up and warm-up conditions, by analogy with the tests of the Chevrolet Cruze engine, the engine of the Lada Granta car was tested, including the first and second stages. The dependency graphs shown in Fig. 4, were supplemented with data of $\mathrm{O}_{2}$ content in the exhaust gas.

Comparison of the test results in Figures 3 and 4 shows that the behavior of experimental curves for $\mathrm{CH}$ and $\mathrm{CO}$ during startup and subsequent warm-up of the tested engines is approximately the same. The difference in absolute values can be explained by different approaches to mixture formation, embedded in the ECU software. While the Chevrolet Cruze engine with a mixture of $\lambda \leq 1$ demonstrates an $\mathrm{O}_{2}$ deficiency and there is some reserve for reducing the $\mathrm{CH}$ emission even under normal conditions, the Lada Granta engine with $\lambda>1$ has a slight excess of $\mathrm{O}_{2}$ and, accordingly, the $\mathrm{CH}$ content is lower. However, it should be noted that too lean mixture at the considered modes can cause misfires and skipping work cycles, which in turn will lead to increase in $\mathrm{CH}$. In addition, excessive depletion of mixture is often accompanied by jerks and other disturbances when driving a car with an unheated engine. 


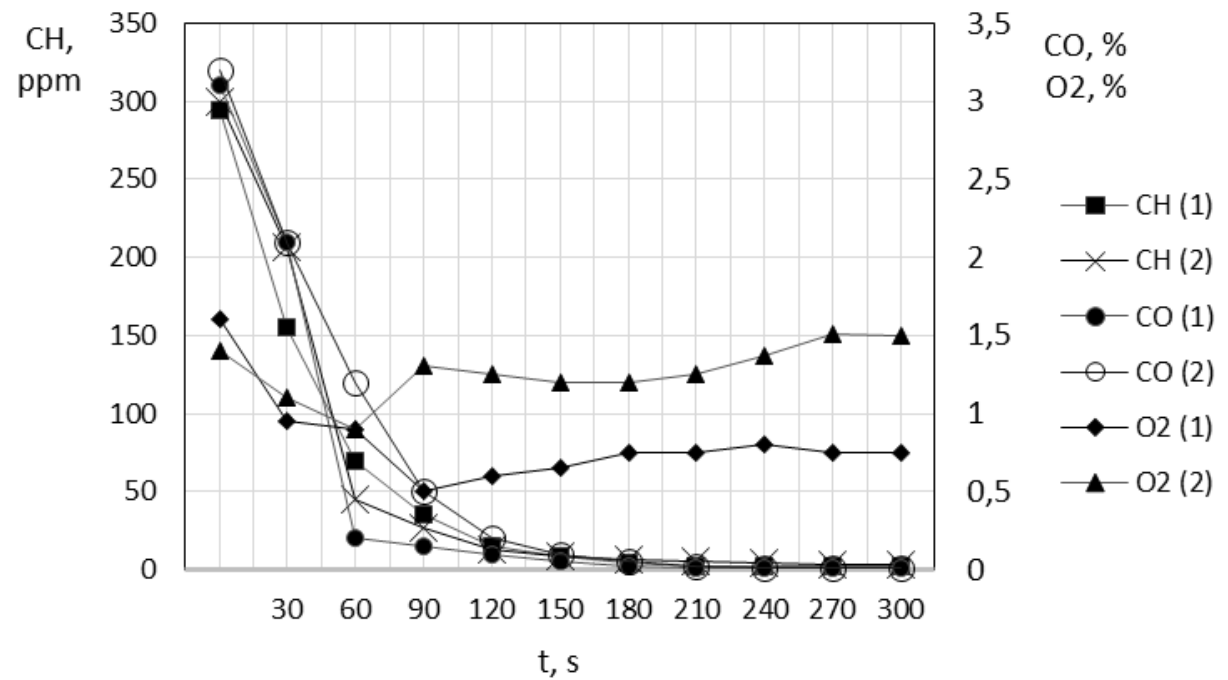

Fig. 4. $\mathrm{CH}, \mathrm{CO}$ and $\mathrm{O}_{2}$ contents versus operating time (Lada Granta engine, cold start): $\mathrm{CH}$ (1), $\mathrm{CO}$ (1) and $\mathrm{O}_{2}$ - values at the first stage of testing under normal conditions; $\mathrm{CH}(2), \mathrm{CO}$ (2) and $\mathrm{O}_{2}-$ values at the second stage without $\mathrm{O}_{2}$ sensor.

Test results for the second cycle are presented in Fig. 5 and Fig. 6 where the contents of individual components in the exhaust gas and the approximate composition of mixture $\lambda$ are shown, calculated according to the gas analysis data at the operating modes listed above. In transient conditions the values of all components are fixed at the time of maximum values of $\mathrm{CH}$ and $\mathrm{CO}$.

To evaluate the efficiency of the converter at various operating modes, including modes with malfunctions, the exhaust gas was selected in different locations. At the first stage of testing exhaust gas selection was carried out in the usual way from a standard exhaust system. At the second stage the exhaust gas was taken from the fitting installed before the converter at the control $\mathrm{O}_{2}$ sensor mounting point. In this case, the control $\mathrm{O}_{2}$ sensor was disconnected and, therefore, the engine control system worked as an open circuit. 


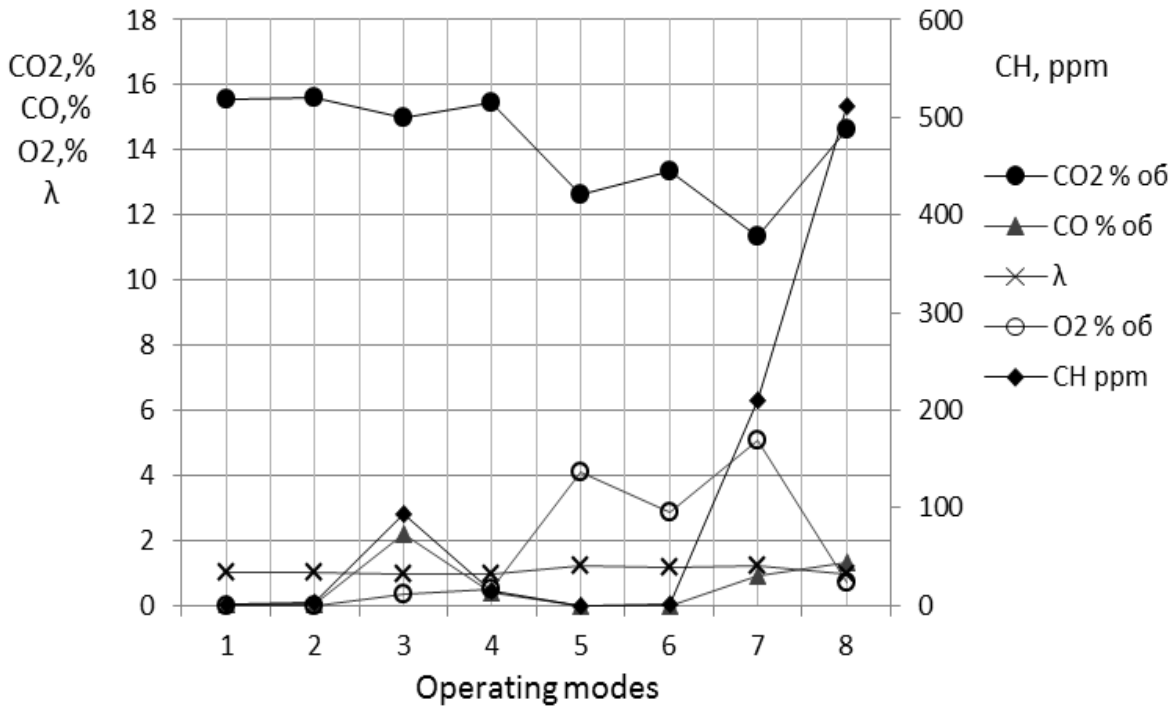

Fig. 5. Contents of individual components in the exhaust gases and mixture composition $\lambda$ at various engine operating modes (Chevrolet Cruze engine, gas selection from the exhaust pipe): $1-$ idle at $\mathrm{n}=$ $1000 \mathrm{rpm} ; 2$ - idle at $\mathrm{n}=3000 \mathrm{rpm} ; 3$ - acceleration from $\mathrm{n}=1000 \mathrm{rpm}$ to $\mathrm{n}=3000 \mathrm{rpm} ; 4$ - braking from $\mathrm{n}=3000 \mathrm{rpm}$ to $\mathrm{n}=1000 \mathrm{rpm} ; 5-$ idle at $\mathrm{n}=1000 \mathrm{rpm}$ with the nozzle turned off; 6 - idle at $\mathrm{n}$ $=3000 \mathrm{rpm}$ with the nozzle turned off; $7-$ idle at $\mathrm{n}=1000 \mathrm{rpm}$ with a faulty spark plug; 8 -idle at $\mathrm{n}$ $=3000 \mathrm{rpm}$ with a faulty spark plug.

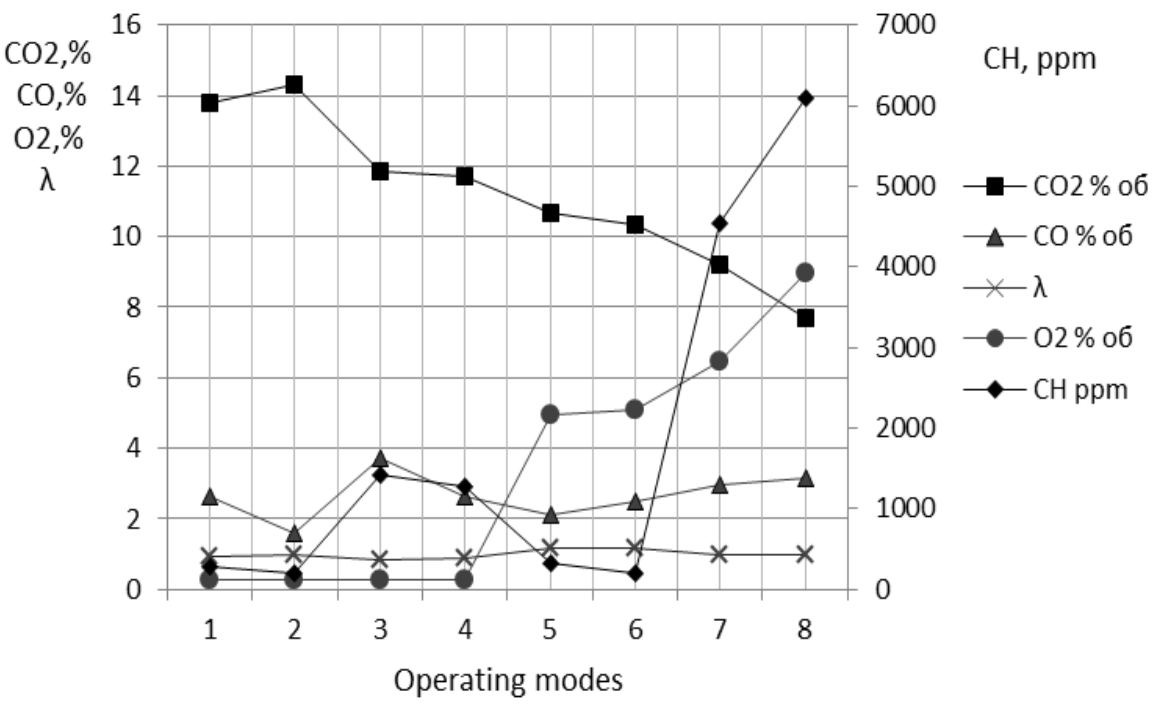

Fig. 6. Contents of individual components in the exhaust gases and mixture composition $\lambda$ at various engine operating modes (Chevrolet Cruze engine, gas selection before the converter): $1-$ idle at $\mathrm{n}=$ $1000 \mathrm{rpm} ; 2$ - idle at $\mathrm{n}=3000 \mathrm{rpm} ; 3$ - acceleration from $\mathrm{n}=1000 \mathrm{rpm}$ to $\mathrm{n}=3000 \mathrm{rpm} ; 4$ - braking from $\mathrm{n}=3000 \mathrm{rpm}$ to $\mathrm{n}=1000 \mathrm{rpm} ; 5-$ idle at $\mathrm{n}=1000 \mathrm{rpm}$ with the nozzle turned off; 6 -idle at $\mathrm{n}$ $=3000 \mathrm{rpm}$ with the nozzle turned off; $7-$ idle at $\mathrm{n}=1000 \mathrm{rpm}$ with a faulty spark plug; 8 -idle at $\mathrm{n}$ $=3000 \mathrm{rpm}$ with a faulty spark plug. 
The results shown in Fig. 5 and Fig. 6 demonstrate that when exhaust gas is taken from a standard exhaust system and a three-component catalytic converter is functioning, the emissions of $\mathrm{CH}$ and $\mathrm{CO}$ at steady state are close to zero. There is a certain surge in the values of these components at the transition mode (mode 3), due to the short-term enrichment of the mixture. Nevertheless, the $\mathrm{CH}$ emissions during the considered transitional modes after the converter are reduced by an order of magnitude compared to emissions before the converter.

Turning off one cylinder by switching off the nozzle (modes 5 and 6) does not cause a noticeable increase of $\mathrm{CH}$ and $\mathrm{CO}$ emissions compared with emissions of a serviceable engine during exhaust gas extraction from a regular exhaust system due to the excess $\mathrm{O}_{2}$ in the exhaust gas. In this case, short-term shutdown of a cylinder does not endanger the normal operation of the converter.

A different picture is present if the cylinder is turned off due to the absence of a spark and with a working nozzle (modes 7 and 8). Such a malfunction immediately increases the emission of $\mathrm{CH}$ by many times in comparison with the emissions of a serviceable engine. Although in this case, the $\mathrm{CH}$ emission (exhaust gas extraction after the converter) is still an order of magnitude lower than before the converter, which demonstrates its efficiency. However, even short-term work with such a defect is dangerous, since a significant part of fuel burns out within the converter, heating it to unacceptable temperatures and destroying its structure. The above example shows that even random misfires caused by defects in the ignition system are extremely undesirable due to a sharp increase of $\mathrm{CH}$ emissions and risk of converter failure. Therefore, in most modern cars the control system turns off the nozzle in a cylinder should the misfires occur.

The obtained data can be used to assess the effectiveness of the converter at considered modes and under the influence of operational factors in the form of the following expression:

$$
E=\frac{C_{\text {in }}-C_{\text {out }}}{C_{i n}}=\frac{\Delta C}{C_{i n}},
$$

where $E$ - toxic component reduction effectiveness, $C_{i n}-$ content of the toxic component before the converter, $C_{o u t}$ - content of the toxic component after the converter, $\Delta C$ - the difference of contents of the toxic component before and after the converter.

Then, according to the data of the tests performed, it is possible to plot the graphs of the effectiveness of the converter on reducing $\mathrm{CH}\left(\mathrm{E}_{\mathrm{CH}}\right)$ and $\mathrm{CO}\left(\mathrm{E}_{\mathrm{CO}}\right)$. Fig. 7 shows the $\mathrm{E}_{\mathrm{CH}}$ and $\mathrm{E}_{\mathrm{CO}}$ values for the start-up and warm-up modes of the Chevrolet Cruze engine calculated according to equation (1) based on the data in Fig. 3. Fig. 8 shows the discrete quantities of the same values according to Fig. 5, 6 . 


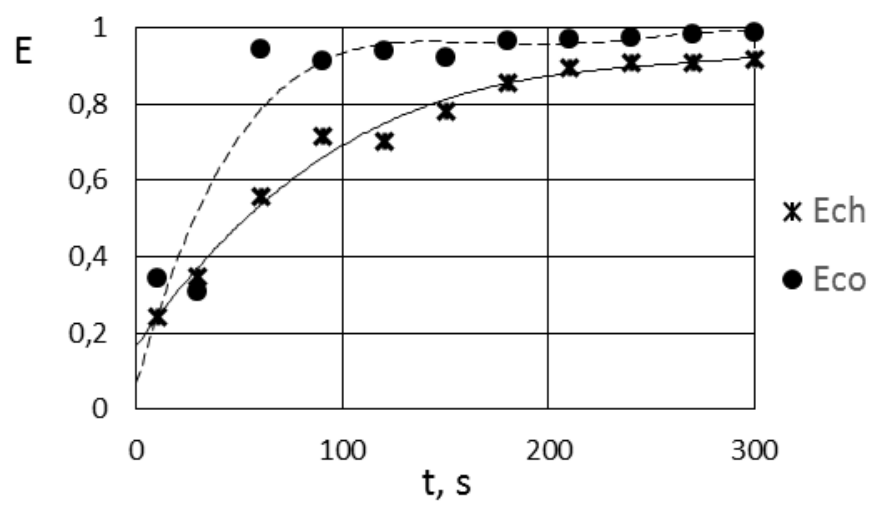

Fig. 7. Values of toxic component reduction effectiveness (E) versus operating time for Chevrolet Cruze engine (cold start, warm-up).

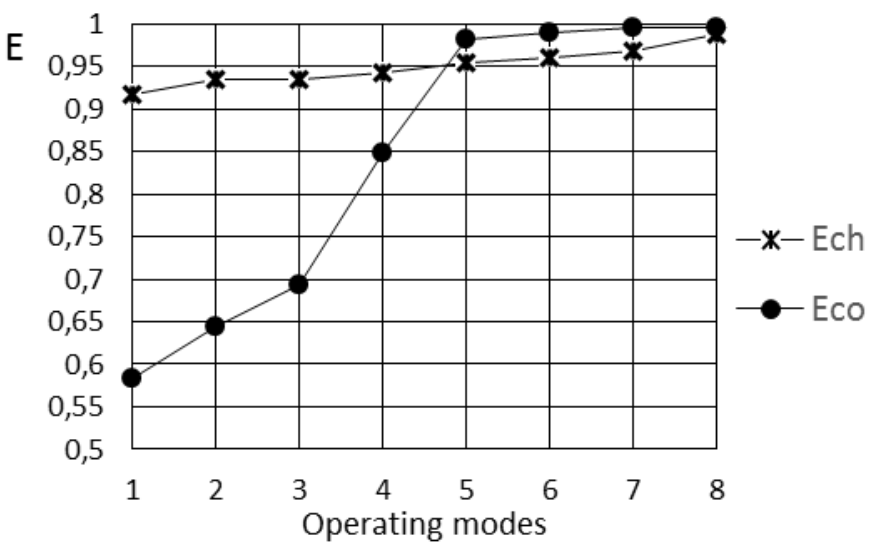

Fig. 8. Values of toxic component reduction effectiveness (E) for Chevrolet Cruze engine at different operating modes: 1 -idle at $\mathrm{n}=3000 \mathrm{rpm}$ with a faulty spark plug; 2 - acceleration from $\mathrm{n}=1000$ rpm to $n=3000 \mathrm{rpm} ; 3$ - idle at $\mathrm{n}=1000 \mathrm{rpm}$ with a faulty spark plug; 4 - braking from $\mathrm{n}=3000$ rpm to $\mathrm{n}=1000 \mathrm{rpm} ; 5-$ idle at $\mathrm{n}=3000 \mathrm{rpm} ; 6-$ idle at $\mathrm{n}=1000 \mathrm{rpm} ; 7-$ idle at $\mathrm{n}=1000 \mathrm{rpm}$ with the nozzle turned off; 8 -idle at $\mathrm{n}=3000 \mathrm{rpm}$ with the nozzle turned off.

In the graphs, all values of $\mathrm{E}$ fall within the range between a zero (in the absence of the reduction of toxic component) and a value of 1.0 (at the highest possible efficiency of reduction). Parameter E with some assumptions can be considered as the criterion of the converter operability for the engine operating in urban conditions. Given the relatively low content of toxic components at the stoichiometric mixture before the converter, values of $\mathrm{E}$ above 0.9 may well be considered an acceptable result of checking its performance.

At the start-up and warm-up modes, the $E_{\mathrm{CO}}$ values (Fig. 7) exceed 0.9, starting from the moment the $\mathrm{O}_{2}$ sensor is turned on, which indicates a high efficiency of $\mathrm{CO}$ reduction. At the same time, the increase in $\mathrm{E}_{\mathrm{CH}}$ values after a cold start is not so drastic. That can be explained by insufficient warm-up of the converter and low content of $\mathrm{O}_{2}$ for sustaining the reaction of oxidation.

The graphs of $\mathrm{E}_{\mathrm{CH}}$ and $\mathrm{E}_{\mathrm{CO}}$ for individual modes of a heated engine, as well as under the influence of operational factors, are plotted as the value of $E$ increases (Fig. 8). The lowest values of $\mathrm{E}$ are predictably observed when a faulty spark plug is installed. Moreover, the $E_{C H}$ values exceed the $E_{C O}$ values and amount to about 0.9 , despite the excessive content of $\mathrm{CH}$. In this case, the high temperature of the converter and the high content of free $\mathrm{O}_{2}$ in the 
exhaust gases contribute to the efficiency of $\mathrm{CH}$ reduction (Fig. 5, 6). In the absence of malfunctions in the engine, a decrease of $\mathrm{E}_{\mathrm{CO}}$ is observed at the acceleration and braking modes due to the deviation of mixture from the stoichiometric.

A more detailed analysis of the obtained values of $E$ shows that some discrete data do not always logically explained and may be the result of measurement errors. However, in general the proposed criterion for evaluating the performance of the converter allows to determine the most problematic modes and factors that impede the implementation of ecological standards for $\mathrm{CO}$ and $\mathrm{CH}$ emissions in urban conditions for a specific automobile engine.

\section{Conclusions}

A general quantitative assessment of influence of individual operational modes and factors on $\mathrm{CH}$ and $\mathrm{CO}$ emissions with the selection of exhaust gases before and after the catalytic converter is given. The most unfavorable regimes and factors contributing to the increased emission of named toxic components are determined.

Under operating conditions of cold start and warm-up conventional serviceable converters are able to reduce the content of $\mathrm{CH}$ and $\mathrm{CO}$ in the exhaust gas by an order of magnitude, provided that the control $\mathrm{O}_{2}$ sensor is immediately turned on. The efficiency of reduction depends on activation time of the control $\mathrm{O}_{2}$ sensor and amount of residual $\mathrm{O}_{2}$ in the exhaust gas. The lack of $\mathrm{O}_{2}$ content in the exhaust gas can be compensated for by the depletion of the mixture by adjusting the ECU or by installing an additional air supply to the converter.

With the engine fully warmed up and a working control circuit from the $\mathrm{O}_{2}$ sensor the standard converter effectively reduces the emissions of $\mathrm{CH}$ and $\mathrm{CO}$ to the minimum values at modes that represent typical urban driving cycle modes. Of the operational defects considered, skipping of operating cycles caused by malfunctions in the ignition system is the defect that most affects the emissions of $\mathrm{CH}$. Turning off the fuel supply in a faulty cylinder allows us to temporarily eliminate the influence of the aforementioned malfunction on $\mathrm{CH}$ emissions and maintain the operability of the converter.

Based on the results of the converter performance test a criterion is proposed for evaluating the effectiveness of reducing the content of $\mathrm{CH}$ and $\mathrm{CO}$ in all considered modes and under the influence of operational malfunctions. This criterion allows to determine the most problematic modes and operational factors inherent in the tested car engine.

The practical importance of the proposed method for assessment of the condition of converter consists in the possibility of using the test results to determine the reserves for reducing toxic components in the vehicle exhaust gas in cases of exceeding the established standards.

\section{References}

1. V. Lozhkin, O. Lozhkina, Transport. Res. Part D 36, 178-189 (2015) DOI: 10.1016/j.trd.2015.02.013

2. V. Lozhkin, O. Lozhkina, V. Dobromirov, Transport. Res. Proc., 36, 453-458 (2018) DOI: $10.1016 /$ j.trpro.2018.12.124

3. K. Prashant, Int. J. of Sc. and Res, 30-33 (2016)

4. M. Pardiwala Julie, P. Femina, P. Sanjay, Int. Conf. on Current Trends in Technol., NUiCONE, 1-6 (2011) 
5. G. Jianbing, T. Guohong, A. Sorniotti, A. EceKarci, R. Di Palo, Appl. Therm. Eng. 14725, 177-187 (2019) DOI: 10.1016/j.applthermaleng.2018.10.037

6. H. Chen, K. Koo, J. Rieck et al., SAE Int. Fuels Lubr., 480-488 (2014) DOI: 10.4271/2014-01-1509

7. C. McAtee, G. McCullough, R. Douglas, Proc. IMechE, Part D: J. of Automob. Eng. 226 (11), 1536-1546 (2019) https://doi.org/10.1177/0954407012446911

8. Dorit, D. Elyse, University of Pittsburgh, Swanson School of Engineering (2013) DOI: 10.1088/1757-899X/197/1/012026

9. Roberts, R. Brooks, P.Shipway, Energy Conversion and Management 82, 327-350 (2014) DOI: 10.1016/j.enconman.2014.03.002

10. S. Dey, G. C. Dhal, D. Mohan, R. Prasad, J. of Traffic and Transport. Eng. (English Edition) 6 (5), 419-440 (2019) DOI: 10.1016/j.jtte.2019.06.002

11. S. Chalapathi, C. Murthy Bhavanarayana, S.B. Pkumar, Int. J. for Res. in Appl. Sc. \& Eng. Technol. 2, 321-333 (2014)

12. Shen, 1. Chang, H. Chen, Z. Zhang, Bo Wang, Y. Wang, Energy Conversion and Management 1971, №111893 (2019) DOI: 10.1016/j.enconman.2019.111893

13. D. Wang, H. An, J. Gong, N. Currier, Yezerets, SAE Technical Papers (2019) DOI: 10.4271/2019-01-0998

14. P. Karuppusamy, R. Senthil Int. J. of Res. in Eng. \& Adv. Technol. 1, 1-6 (2013)

15. R. Makwana Narendrasinh, M. Amin Chirag, K. Dabhi Shyam, Int. J. of Adv. Eng. Technol. 4, 10-13 (2013)

16. Promit, D. Srisha, Int. J. of Adv. Sc., Eng. and Technol. 3, 19-23 (2014)

17. S. Venkatesan, D. Uday, B. Hemant, G. Kumar, K. Kumar, IOP Conf. Ser.: Materials Sc. and Eng. 197 (1) (2017)

18. P.H.B. Zárante, J.R. Sodré, J. Natural Gas Sc. and Eng. 1 (6), 216-220 (2009) DOI: 10.1016/j.jngse.2009.11.002 